Marie-Dominique Charlier-Dagras, La laïcité française à l'épreuve de l'intégration européenne.Pluralisme et convergences

Préf. de Danièle Lochak. Paris, L'Harmattan, coll. « Logiques juridiques », 2002, 447 p.

Bérengère Massignon

\title{
OpenEdition
}

Édition électronique

URL : http://journals.openedition.org/assr/3894

DOI : 10.4000/assr.3894

ISSN : $1777-5825$

Éditeur

Éditions de l'EHESS

Édition imprimée

Date de publication : 1 décembre 2006

Pagination : 115-283

ISBN : 2-7132-2124-2

ISSN : 0335-5985

Référence électronique

Bérengère Massignon, « Marie-Dominique Charlier-Dagras, La laïcité française à l'épreuve de l'intégration européenne.Pluralisme et convergences ", Archives de sciences sociales des religions [En ligne], 136 | octobre - décembre 2006, document 136-26, mis en ligne le 12 février 2007, consulté le 21 septembre 2020. URL : http://journals.openedition.org/assr/3894 ; DOI : https://doi.org/10.4000/assr.3894

Ce document a été généré automatiquement le 21 septembre 2020.

(C) Archives de sciences sociales des religions 


\section{Marie-Dominique Charlier-Dagras, La laïcité française à l'épreuve de l'intégration européenne.Pluralisme et convergences}

Préf. de Danièle Lochak. Paris, L'Harmattan, coll. « Logiques juridiques », 2002, 447 p.

\section{Bérengère Massignon}

1 Utile synthèse ou indigeste compilation ? L'appréciation reste difficile tant ce livre, issu d'une thèse, aborde de sujets aussi divers que l'histoire de la laïcité depuis la Révolution française et ses mutations récentes au vu de la jurisprudence; la comparaison des systèmes de relations Églises-État des quinze pays de l'Union européenne dans leurs différences et leurs convergences, notamment à l'aune du traitement de l'islam; la législation de la Cour européenne des droits de l'Homme en matière de liberté religieuse et les prémices d'une législation communautaire et d'un dialogue entre l'Union européenne et les religions, le tout rapporté au cas français, mais de manière non systématique. Chacun de ces thèmes appellerait en soi une étude spécifique. La difficulté est doublée par la multiplication des éclairages apportés: historiques, politiques, sociétaux et juridiques, sans qu'aucune méthode ne domine, ce qui prive l'ouvrage de la rigueur propre que chaque discipline offre en termes de raisonnement, d'analyse des sources et de hiérarchisation des facteurs explicatifs.

2 Ainsi, la première partie s'axe autour de la dimension duale de la laïcité française entre volonté de séparation stricte et garantie de la liberté religieuse. Cette grille de lecture, assez classique au demeurant, permet de souligner les ambiguïtés du principe de laïcité et les fluctuations de ses mises en œuvre législatives, jurisprudentielles et administratives. Pourtant, l'analyse ne tranche pas entre une interprétation historique et juridico-philosophique. La première mettrait en lumière les rapports de forces et les compromis politiques et permettrait d'expliquer les tensions, les contradictions et les évolutions de la gestion des cultes en France, à la manière de Jean Baubérot qui lit 
l'histoire de la laïcité française en terme de " pacte » (référence quasi-absente du livre). La deuxième insisterait sur la concurrence des libertés, leur caractère potentiellement antagoniste et la difficulté pour le législateur et le juge de les concilier ou de les hiérarchiser. Ces deux pistes sont abordées mais aucune n'est exploitée de manière systématique.

De même, la seconde partie expose avec justesse la convergence des modèles européens de relations Églises-État confrontés aux mêmes défis de la mondialisation, de l'intégration européenne, de la pluralisation de la scène religieuse et de la dérégulation du croire. Mais les mécanismes juridiques et politiques par lesquels s'opère un difficile équilibre entre pluralisme juridique et harmonisation législative supranationale ne sont pas pleinement explicités. Pareillement, la présentation typologique des systèmes de cultes en Europe souffre d'une imprécision terminologique : la notion de «fusion institutionnelle » est impropre; seuls la théocratie et le totalitarisme présentent une fusion du religieux et du politique par l'absorption de l'un ou de l'autre. Par ailleurs, les différentes réalités que ce terme désigne chez l'auteure: "Église d'État», "Église établie », «Église nationale » ou «État confessionnel » ne sont pas clairement définies et distinguées, d'où l'impression d'une énumération fastidieuse plus que d'une analyse heuristique.

4 Mais l'importance des notes (couvrant parfois les trois quarts de la page) renforce l'impression de lire une thèse à l'état brut plutôt qu'un livre. Reste l'excellente et impressionnante bibliographie sur laquelle s'appuie l'ouvrage et qui en fait un outil de travail intéressant. 